\title{
MYOCARDIAL PROTECTION DURING CARDIOPLEGIA IN OPEN-HEART SURGERY: A REVIEW
}

\author{
R.R. Chatrath, T.K. Kaul and D.R. Walker
}

\begin{abstract}
A BSTRACT
The use of cardioplegia (pharmacologically induced electromechanical arrest) to achieve the ideal conditions for cardiac surgical operations was introduced over 20 years ago in clinical practice. Since then a number of ingredients have been added in various proportions to different cardioplegic solutions and their evaluation in experimental laboratories and clinical practice has continued. Any additive to a cardioplegic solution should be investigated in experimental laboratories and asanguinous cardioplegic solutions should be carefully formulated to avoid extremes of ionic concentrations, $\mathrm{pH}$ and osmolarity. Cold blood cardioplegia has not been found advantageous when compared with conventional asanguinous solutions. $A$ combination of pharmacologically induced arrest with cold asanguinous cardioplegic solution and topical hypothermia protects the myocardium better than topical hypothermia alone or normothermic cardioplegia, and continuous infusion of cardioplegic solutions has proved no better than multidose administration. Multidose administration of cold cardioplegic solutions with moderate hypothermia and surface cooling has been found most satisfactory for prolonged aortic cross clamping (up to, two hours). Use of cardioplegia in recent years has undoubtedly improved the prognosis of a number of patients undergoing surgical correction of complex cardiac lesions.
\end{abstract}

CARDIAC SURGICAL PROCEDURES often require a bloodless, relaxed and motionless field during operation, which is easily accomplished by ischaemic arrest induced by cross clamping the aorta. Any period of ischaemia is accomplished by metabolic and structural changes which determine the functional recovery of the heart in the postoperative period. The safe period of ischaemia for the human heart is not clearly defined but $20-30$ minutes is generally considered the upper limit. When aortic cross clamping time exceeds this period substantial subendocardial necrosis may occur, with low output syndrome in the postoperative period. The need for protection of the myocardium during ischaemic arrest has been well recognized and a number of methods including local ${ }^{1}$ and systemic hypothermia, ${ }^{2}$ intermittent coronary perfusion, ${ }^{3}$ retrograde coronary perfusion with cold blood, ${ }^{4}$ coronary perfusion with cold lactated Ringer's solution, ${ }^{5}$ tetrodoxin, ${ }^{6}$ acetylcholine ${ }^{7}$ chemical asanguinous $\mathrm{K}^{+}$ cardioplegia, ${ }^{8}$ cold blood cardioplegia, ${ }^{9}$ have been used in experimental studies and clinical practice. Of these, hypothermia and pharmacological arrest with cold cardioplegic solutions have now gained wide acceptance in clinical practice.

Department of Anaesthesia and Cardiovascular Unit, Killingbeck Hospital, Leeds, England.

Reprint requests to Dr. R.R. Chatrath, Consultant Anaesthetist, Killingbeck Hospital, Leeds, LS $146 \mathrm{UQ}$, England.

Canad. Anaesth. Soc. J., vol. 27, no. 4, July 1980

\section{Methods of Myocardial Protection}

\section{Topical hypothermia}

Hypothermia has been proved to be an effective method of myocardial preservation. It provides a bloodless arrested heart, lowers the energy requirements, ${ }^{10}$ delays the depletion of high energy phosphate reserves and lactic acid accumulation, and retards the morphological and functional deterioration associated with ischaemic arrest. ${ }^{11}$ The technique of topical cooling with continuous irrigation of the surface of the heart was first used by Shumway, et al. ${ }^{12}$ The cooling proceeds from the surface to the interior and is unlikely to cool the subendocardium and the interventricular septum due to mediastinal and bronchial collateral return, which would warm the endocardial surface without profound hypothermia. ${ }^{13,14}$ Moderate hypothermia and surface cooling have been generally found inadequate to protect the myocardium for more than one hour of ischaemic arrest. ${ }^{13,15}$ Deep hypothermia and surface cooling, have been sufficient for 90 minutes of ischaemic arrest. ${ }^{16}$ Profound cooling of the myocardium is known to cause myocardial damage due to crystallization of the membrance lipids and poor ventricular performance on perfusion. ${ }^{17,18}$

\section{Cardioplegia}

The concept of pharmacological arrest (cardioplegia) was initially introduced by Hooker in 
$1929,{ }^{19}$ although the ability of $\mathrm{K}^{+}$to arrest the heart in diastole was known for a long time. ${ }^{20} \mathrm{On}$ application of the aortic cross clamp, even with topical hypothermia, the cardiac arrest does not occur immediately. The mechanical arrest is preceded by agonal contractions and ventricular fibrillation during which high energy substances are depleted. ${ }^{21}$ The pharmacological arrest renders the heart electrically and mechanically inert, thereby producing a low energy state of asystole immediately. A normothermic hyperkalaemic solution was initially used to induce pharmacological arrest; ${ }^{22}$ since then a number of other constituents have been added to cardioplegic infusates. Cold cardioplegic solutions are definitely advantageous and protect the myocardium by virtue of their cooling effect and added components. When injected into the aortic root after cross clamping the cold cardioplegic solutions are distributed throughout the myocardium by natural pathways, thus producing homogenous cooling of the myocardium. The myocardial energy requirements, ${ }^{23}$ oxygen debt, ${ }^{15}$ and accumulation of metabolites which inhibit the anaerobiosis is prevented, ${ }^{24}$ the subendocardium is well protected and the haemodynamic instability as a result or poor myocardial contractility and reduced compliance associated with ischaemic arrest is considerably reduced. ${ }^{25}$

\section{Constituents of the cardioplegic solutions}

A number of constituents have been added in various concentrations in different cardioplegic solutions. The potassium, magnesium and procaine contained in the cardioplegic solution induce pharmacological arrest ${ }^{26}$ steroids, procaine, glucose, 14 magnesium and high energy phosphates 27 have been used as membrane stabilisers. Glucose, ${ }^{27.28}$ mannitol, ${ }^{29}$ sorbitol $^{30}$ have been used as hyperosmotic solutions; bicarbonate, phosphate, THAM have been added as buffering agents. ${ }^{14.31}$ Besides asanguinous cold cardioplegic solutions, cold blood cardioplegic solutions have been used. ${ }^{9}$ Potassium-induced cardioplegia has had a more controversial history as a mode of myocardial preservation. Potassium causes ionic paralysis of the cellular membrane transport system ${ }^{32}$ by blocking the initial fast (inward sodium current) phase of myocardial cellular depolarisation ${ }^{33}$ and thus preserves the energy reserves for the maintenance of integrity of cell membranes and active transport of $\mathrm{Na}-\mathrm{K}$ pump. ${ }^{34}$ Following the initial experimental studies, ${ }^{35}$ Melrose Solution containing 245$980 \mathrm{mg} \mathrm{K}^{+} /$/litre $^{8}$ was advocated and used.
Several authors have reported poor or ineffective myocardial contractility or left ventricular failure in the postoperative period with Melrose's Solution. ${ }^{36.37}$ The unfavourable reports eventually led to the discontinuation of Melrose's potassium containing cardioplegic solution. More recently potassium induced arrest was reinvestigated using isotonic cardioplegic solution containing $\mathrm{K}^{+}$in the concentration of $10-15 \mathrm{mg} /$ litre, with good results. ${ }^{38}$ Concentrations of $25 \mathrm{mmol} / \mathrm{l}$ of $\mathrm{K}^{+}$ in cardioplegic solutions for the isolated rat heart preparation and $25-34 \mathrm{mmol} / \mathrm{l}$ for the human patient have been considered optimal for good postoperative recovery. ${ }^{34}$

Magnesium and procaine are also effective cardioplegic agents and augment the arrest induced by $\mathrm{K}^{+} ; 26$ but unlike potassium, both are systemically toxic when absorbed in any quantity. In pharmacological concentration both block the initial depolarization by their effects on transmembrane ion movement. ${ }^{33}$ Magnesium also exerts a beneficial effect through blockage of intracellular metabolism. ${ }^{30}$ Magnesium aspartate has been considered more advantageous as it accelerates the regeneration of ATP from inosine phosphate. ${ }^{28}$ Procaine hydrochloride is a potential membrane stabiliser, ${ }^{39}$

Addition of hyperosmotic solutions of sorbitol, ${ }^{30}$ mannitol, ${ }^{29}$ and plasma proteins has been found universally beneficial; addition of glucose and insulin to cardioplegic solutions was beneficial due to its hyperosmolarity and stimulation of glycolysis, while multidose or continuous infusions of cardioplegic solution were used, ${ }^{28,40}$ but was found detrimental due to hyperosmolarity and enhanced anaerobiosis in the isolated rat heart preparation after global ischaemia with stagnant coronary circulation. ${ }^{41}$

The cellular metabolic processes (e.g. membrane pump) are $\mathrm{pH}$ dependant. ${ }^{42}$ Bicarbonate. inorganic phosphates and THAM ${ }^{39}$ have been used as buffcring agents to minimize the ischaemic injury. Inorganic phosphates have been considered better as buffering agents than bicarbonates. ${ }^{13}$

Cold blood cardioplegic solutions have been used both experimentally and in clinical practice with satisfactory results due to higher oxygen carrying capacity. ${ }^{33}$ The possible demerits of cold blood cardioplegia are rouleau $x$ formation, ${ }^{43}$ poor control of ionic composition and presence of undesirable products of extracorporeal circulation, such as catecholamines. ${ }^{33}$ Routine screening for cold agglutinins should be done. ${ }^{9}$ Some groups using cold blood cardioplegia consider it 
unwise to lower the temperature of the solution below $20^{\circ} \mathrm{C}$, even in the absence of demonstrated cold agglutinins. ${ }^{43}$

Infusion of asanguinous cardioplegic infusates has been known to cause calcium paradox, and during reperfusion myofibrillar contracture, stone heart phenomenon in vitro. ${ }^{38}$ Addition of calcium to asanguinous infusates is, however, known to avoid deleterious cell membrane changes. ${ }^{29}$

\section{Cardioplegic solutions in clinical use}

A number of cardioplegic solutions have been compared and used by varying the concentrations of the constituents already mentioned. Following are some of the commonly used cardioplegic solutions:

1. Kirsch's Solution ${ }^{30}$ has been in use by a variety of European surgeons since 1969. It consists of:

Magnesium aspartate 2.5 per cent

Potassium hydrochloride 0.3 per cent

Sorbitol 4.5 per cent

Cardiac arrest is achieved by $\mathrm{Mg}^{++} \mathrm{K}^{+}$and sorbitol is added to reduce oedema; $50 \mathrm{ml}$ of this solution injected into the aortic root is sufficient to induce cardiac arrest.

2. Bretschneider's Solution ${ }^{29}$ has been used in Europe since 1964. The composition is:

Solution I

$\mathrm{Na}+50-60 \mathrm{mmol} / \mathrm{l}$

$\mathrm{K}^{+} 1.5-2 \mathrm{mmol} / \mathrm{l}$

$\mathrm{Mg}^{++} 0.5-2.5 \mathrm{mmol} / 1$

Glucose $0.5-1 \mathrm{mmol} / \mathrm{l}$

Procaine 0.2 per cent

Mannitol $320 \mathrm{~m}$ osm.

$\mathrm{cH}^{+} 39.81 \mathrm{nmol} / 1(\mathrm{pH} 7.4)$

Solution 2

$10 \mathrm{mmol} / \mathrm{l}$

$5 \mathrm{mmol} / \mathrm{l}$

$1.0 \mathrm{mmol} / \mathrm{l}$

0

0.2 per cent

$320 \mathrm{~m}$ osm.

$\mathrm{cH}^{+} 39.81 \mathrm{nmol} / \mathrm{l}(\mathrm{pH} 7.4)$

One litre of solution, followed by 1 litre of solution 2, are infused 2-3 minutes into the aorta.

3. Buckberg's solution consists of:

Plasmanate $850 \mathrm{ml}$

Salt poor albumen, $50 \mathrm{ml}$

$\mathrm{KCL} 30 \mathrm{mmol} / 1$

Glucose 50 per cent $40 \mathrm{ml}$

Insulin 40 units

THAM E $20 \mathrm{mls}$
Temperature $4-10^{\circ} \mathrm{C}$

$\mathrm{Na}^{+} 91 \mathrm{mmol} / \mathrm{l}$

$\mathrm{K}^{+} 30 \mathrm{mmol} / \mathrm{l}$

$\mathrm{Cl}^{-} 73 \mathrm{mmol} / 1$

$\mathrm{Ca}^{++} 2 \mathrm{mmol} / \mathrm{l}$

$\mathrm{HCO}^{-} 20 \mathrm{mmol} / \mathrm{l}$

Insulin 40 units/I

Protein $3.5 \mathrm{~g} / \mathrm{l}$

Osmolarity $320 \mathrm{~m}$ osm/l

$250 \mathrm{ml} / \mathrm{minute}$ are injected through the aortic root for the first minute followed by $150 \mathrm{ml} / \mathrm{minute}$ for a further two minutes.

4. St. Thomas Solution ${ }^{26}$ consists of:

$\mathrm{MgCl}_{2} \cdot 6 \mathrm{H} 20,16 \mathrm{mmol} \quad 3.553 \mathrm{~g}$

$\mathrm{KCL}, 16 \mathrm{mmol} \quad 1.93 \mathrm{~g}$

Procaine hydrochloride, $1 \mathrm{mmol}, 0.2728 \mathrm{~g}$ in distilled water, $(10 \mathrm{ml})$

The cardioplegic ampoule is added to one litre of lactated Ringer's solution and cooled to $4^{\circ} \mathrm{C}$ before using. Magnesium and potassium are used to arrest the heart and procaine for membrane stabilisation. St. Thomas's solution is widely used in Britain (including our own unit) for the last two years.

\section{Administration of cardioplegic solutions}

After the establishment of cardiopulmonary bypass and moderate hypothermia, (oesophageal temperature $30^{\circ} \mathrm{C}$ ), the refrigerated cardioplegic solution is brought out just prior to use. The bottle or plastic bag containing the solution is placed at a height of 1.5 metres in a Fenwal pressure bag. The infusion set is connected to a long connecting tube, a part of which is placed in an ice bucket to keep the temperature of the infusates low. An ordinary $2 \mathrm{~mm}$ needle, a flanged needle ${ }^{45}$ (to avoid perforation of the posterior wall of the aorta) or a coronary cannula is connected to the end of the infusion set, and meticulous care is taken to get rid of all air bubbles. After aortic cross clamping, the needle is introduced into the aortic root, in the middle of a superficial purse string, which is then snared and tied to the needle or cannula to prevent dislodgement and to allow multiple infusions. When a plastic bag is used, infusion is maintained with the help of a Fenwal pressure bag to maintain a steady flow at a pressure not exceeding $10.6-13.3 \mathrm{kPa}(80-100 \mathrm{~mm}$ $\mathrm{Hg}$ ) to avoid extravasation and myocardial oedema. In the presence of aortic regurgitation, increasing the rate and volume may help to arrest the heart, but effective transmyocardial cooling might not be achieved and direct injection into the coronary ostia by plastic or metal coronary can- 
nulae is recommended. ${ }^{45}$ The direct cannulation of the coronary arteries may not adequately perfuse the left ventricle if the cannula extends beyond its bifurcation and the infundibulum of the right ventricle may not be protected if it is supplied by a separate conus branch. Damage to coronary ostia would result in infarction during operation or late coronary arterial stenosis. ${ }^{33}$

Administration of a single dose cardioplegia $(20-30 \mathrm{ml} / \mathrm{kg})$ has been a standard practice, but its advantages are limited, due to non-coronary bronchial and mediastinal blood return. ${ }^{14,15}$ Multidose cardioplegia (intermittent re-perfusion) maintains the arrest and cooling and also enhances the washout of lactic acid and other metabolites. ${ }^{10.14 .46}$ Continuous infusion of cardioplegic solution has no advantage over multidose infusion, is cumbersome, and carries the risk of myocardial oedema. ${ }^{33.46}$

We electively reperfuse the myocardium with cardioplegic solution cooled to $4^{\circ} \mathrm{C}$ and topically cool the heart when ischaemic arrest exceeds 30 minutes, to keep myocardial temperature between 15-18 C. After each infusion the purse string around the cannula in the right atrium is released to discard the coronary sinus return to prevent the toxic absorption of some of the constituents and haemodilution. With the help of surface cooling and multidose cardioplegia, good functional recovery after two hours of ischaemia has been well documented. ${ }^{20,39,46}$ Our experimental studies have also indicated similar results when ischaemic arrest exceeds one hour: ${ }^{27}$ we supplement glucose, insulin, potassium, methylprednisolone, sodium bicarbonate and inorganic phosphate (sodium phosphate 0.6 per cent sodium acid phosphate 1.7 per cent) systematically.

Evaluation of cardioplegic solutions and constituents

The beneficial effects of various cardioplegic solutions, their constituents and various modes of administration have been evaluated by studying biochemical structural and functional changes during aortic cross clamping and on reperfusion. The onset of global ischaemia is followed immediately by cessation of the coronary circulation. Consequently a significant fall in the $\mathrm{Pm}_{\mathrm{O}_{2}}$ and the endogenous reserves of A TP and creatine phosphate occurs. ${ }^{21}$ The myocardial glycogen reserves are utilized for anacrobic production of A TP. ${ }^{22}$ The glycolytic production of ATP is considerably low but is essential for the maintenance of cell viability with the remainder of the en- dogenous ATP. ${ }^{47}$ The hydrolysis of ATP is associated with the liberation of hydrogen ions which are neutralized by bicarbonate reserves with the release of carbon dioxide. The glycolytic lactic acid and $\mathrm{Pm}_{\mathrm{CO}_{2}}$ continue to rise due to the stagnant coronary circulation and the intracellular acidosis this produced inhibits the glycolytic enzymes with a further reduction in A TP levels. ${ }^{21}$ A significant preservation of ATP and glycogen levels with the surface hypothermia and single or multidose cardioplegia has been observed, indicating a marked depression of metabolic activity. ${ }^{10}$ The energy thus saved by the electromechanical activity is utilized for the maintenance of cell membrane integrity and ionic transport across the cell membrane. ${ }^{14}$ In spite of the minimal changes in ATP levels, creatine phosphate levels were depleted with surface hypothermia and cold cardioplegia, indicating that creatine phosphate acts as an intermediate store of energy to rebuild ATP levels; thus creatine phosphate is a more sensitive index of the metabolic activity. ${ }^{22}$ Myocardial ATP and creatine phosphate levels, however, fail to return to pre-ischaemic levels on reperfusion after single or multidose cardioplegia, but were significantly higher when compared with unprotected ischaemic myocardium. The levels of ATP and creatine phosphate significantly influence the functional recovery of the myocardium on reperfusion. No data are yet available as to what levels ATP and creatine phosphate should fall to before myocardial injury would be detectable by coronary sinus CPK measurement. ${ }^{22}$ However, a minimal rise in coronary sinus CPK occurred with hypothermia and cold cardioplegia, indicating a minimal myocardial damage. ${ }^{22}$

Total lactate production is an indicator of the total glycolytic activity ${ }^{\mathbf{4 8 , 4 9}}$ and appears to be unrelated to the irreversible injury, indicating that the enhancement of glycolysis was not a prime determinant of the injury ${ }^{50}$ but the tissue lactate accumulation correlated well with irreversible injury. ${ }^{46}$

Electron microscopy is accepted as an efficient tool in detecting early subcellular damage; structural changes have been shown to bear a good correlation with biochemical and functional changes. ${ }^{44,51}$ Ultrastructural changes in the form of intracellular oedema, disruption of myofibrils and mitochondria, appearance of contraction bands, absence of glycogen and deposition of electron dense particles (probably calcium phosphate), have been studied during ischaemia and reperfusion. ${ }^{44}$ The differentiation between rever- 
sible and irreversible injuries have been defined but the point of no return in terms of criteria for cell death has not been defined. The morphological features have shown a better preservation with surface hypothermia and cold cardioplegia and multidose cardioplegia. ${ }^{51}$

During global ischaemia significant oxygen debt occurs, which is repayed on reperfusion by reactive hyperaemia and increased oxygen consumption, which restores the reduced compliance and myocardial contractility caused by ischaemic arrest to pre-ischaemic levels. ${ }^{46}$ The subendocardial layers suffer most from ischaemic injury ${ }^{14}$ and this may result in ischaemic contracture. ${ }^{53}$ Normally subendocardial flow per unit muscle mass is equal to the other myocardial regions, but a marked preferential subendocardial perfusion occurs on reperfusion. ${ }^{25}$ Thus the measurement of subendocardial/epicardial flow, left ventricular oxygen consumption, left ventricular compliance and contractility would give a fairly accurate assessment of the left ventricular functions and evaluation of various cardioplegic solutions and their constituents. . $^{25,39,46}$

The reactive hyperaemia usually persists on reperfusion after aortic cross clamping to facilitate repayment of the oxygen debt incurred during ischaemia. The subendocardium was relatively underperfused with surface hypothermia alone due to post-ischaemic oedema ${ }^{25}$ but an increased subendocardial flow occurred when cold cardioplegia was combined with surface hypothermia and even better results were obtained with multidose cardioplegia ${ }^{39}$ as calculated by modified methods of Rudolph and Heymen. ${ }^{53}$

The augmentation of post-ischaemic oxygen uptake was expected in poorly protected myocardium, but contrary to this assumption augmentation was greater with hypothermia plus single dose cardioplegia and the highest values (or greatest repayment) occurred with multidose cardioplegia and membrane stabilization. ${ }^{25,39}$ The post-ischaemic oxygen uptake was lower after global ischaemia or even topical hypothermia, probably due to diminished oxidative phosphorylation and increased anaerobic metabolism.

The rise in the left ventricular end diastolic pressure may occur due to changes in myocardial compliance due to ischaemic changes in the myocardial wall structure, or change in the ventricular contractility.

Left ventricular compliance was depressed with topical hypothermia alone due to increased subendocardial resistance as a result of post- ischaemic oedema and reduction in ventricular distensibility. ${ }^{25}$ The post-arrest compliance was improved with single dose or multidose cardioplegia with membrane stabilization on reperfusion. ${ }^{25,39.46}$

The isovolumetric ventricular function curves $^{25,39}$ and left ventricular performances assessed by Starling's curve with right heart bypass (values expressed as stroke volume/kg), maximum measured velocity and maximum $\mathrm{dp} / \mathrm{dt}$ give a good indication of myocardial contractility and left ventricular performance on reperfusion. ${ }^{39}$

Myocardial contractility was poorly preserved with topical hypothermia alone ${ }^{25}$ but was well maintained when topical hypothermia plus cardioplegia and multidose cardioplegia were used. ${ }^{39}$

The cardioplegic solutions and their constituents have been tested in acute experiments and the long-term effects of these agents and their preservatives on coronary endothelial surface are unknown. ${ }^{13}$ Late myocardial fibrosis and permanently compromised function is likely to occur in poorly preserved myocardium. ${ }^{25.39}$ A microscopic examination at a later date and chronic evaluation in the experimental situation ${ }^{13}$ will be necessary for their correct evaluation.

Thus the beneficial effects of cardioplegia and its constituents have been evaluated by the measurement of the following parameters.

\section{Biochemical changes \\ Myocardial ATP 22,48 \\ Myocardial creatine \\ phosphate ${ }^{22.48}$ \\ Myocardial CPK 22 \\ $\mathrm{Pm}_{\mathrm{O}_{2}}$ and $\mathrm{Pm}_{\mathrm{CO}_{2}}{ }^{50}$ \\ Coronary sinus lactate and $\mathrm{CPK}^{22}$}

Structural changes ${ }^{4,51,54}$

Interstitial and intracellular oedema

Appearance of contraction band

Myofibril pattern

Mitochondrial and lysosomal changes

\section{Functional changes}

Left ventricular subendocardial/subepicardial blood flow ratio. ${ }^{39}$

Left ventricular oxygen consumption. ${ }^{25.39}$ 
Left ventricular compliance, maximum measured velocityand maximum $\mathrm{dp} / \mathrm{dt}^{25.39,46}$

Left ventricular contractility and performance (stroke vol kg) 25.39 $^{2}$

\section{ACKNOWLEDGEMENT}

The authors are grateful to Miss J.G. Luxton for her secretarial help with the preparation of this manuscript.

\section{REFERENCES}

1. Cross, F.S., Jones, R.D. , Berne, R.M. Localised cardiac hypothermia as an adjunct to elective cardiac arrest. Surgical Forum 8: 355-359 (1957).

2. Stemmers E.A., McCart P., Stanton, W., el al. Functional structural alterations in the myocardium during aortic cross clamping. J. Thoracic \& Cardiovascular Surgery 66: 754-770 (1973).

3. Benzing, G., Stockert, J., Nave, E. \& Kaplan, $S$. Myocardial ischaemia and cardiopulmonary bypass. Cardiovascular Research 7: 186-195 (1973).

4. Poiriek, R.A., Guyton, R.A., McIntosh, C.L.\& Morrow, A.G. Drip retrograde coronary sinus perfusion for myocardial protection during aortic cross clamping. J. Thoracic \& Cardiovascular Surgery 70: 966-973 (1975).

5. Tyers, G.F.O., Williams, E.K., Hughes, K.C. \& TODD, G.J. Effect of perfusate temperature on myocardial protection from ischaemia. J. Thoracic \& Cardiovascular Surgery 78: 766-77I (1976).

6. Tyers, G.F.O., TODD, G.J., Niebaur, I.M., Manley, M.J. \& Waldhausen, J.A. Effect of intracoronary tetrodotoxin on the recovery of the isolated working heart from 60 minutes of ischaemia. Circulation 49: 50: 175-179 (1974).

7. Ebert, P.A., Greenfield, L.J., Austein, W.G., et al. Experimental comparison of methods for protecting the heart during aortic occlusion. Annals of Surgery. 755: 25-32 (1962).

8. Melrose, D.G., Dreger, B., Bentall, H.H. \& BAKER, J.B.E. Elective cardiac arres1. Lancet 2: 21-22(1955).

9. Laks, H., Barner, H.B. \& Kaiser, G. Cold blood cardioplegia. J. Thoracic \& Cardiovascular Surgery 77: 319-322 (1979).

10. Roe, B.B., Hutchinson, J.C. \& Fishman Myocardial protection with cold ischaemic potassium-induced cardioplegia. J. Thoracic \& Cardiovascular Surgery 73: 366-374 (1977).

11. Greipp, R.B., Stinson, E.B. \& Shumway, N.S. Profound hypothermia for myocardial protection during open-heart surgery. J. Thoracic \& Cardiovascular Surgery 66: 731-74I (1973).

12. Shumway, N.F., Lower, R.R. \& Stoffer, R.C. Selective hypothermia of the heart in anoxic cardiac arrest. Surg. Gynae. \& Obst. 129: 750-754 (1959).

13. Levitsky's Intercoronary perfusate for myocardial protection. Ann. Thoracic Surgery 24: 297-298 (1977).

14. BuCKBERG, G.D. Left ventricular subendocardial necrosis. Ann. Thoracic Surgery 24: 299-390 (1977).

15. Gillette, P.C., Pinsky, W.W., Lewis, R.M. Burnet, E.P., Wood, J.M., EntMan, M.L. \& Schwartz, A. Myocardial depression after elective ischaemic arrest. Subcellular biochemistry and prevention. J. Thoracic \& Cardiovascular Surgery 77: 608-618 (1979).

16. TODD, G.J. \& TYERS, G.F.O. Amelioration of the effects of ischaemic cardiac arrest by intracoronary administration of cardioplegic solution. Circulation 52: $1111-1117$ (1975).

17. Angell, W.W., Rikkers, L., Dong, E. \& Shumwar, N.E. Organ viability with hypothermia. J. Thoracic \& Cardiovascular Surgery 58: 619-624 (1969).

18. Maloney, J.V., Cooper, N., Mulder. D.G. \& BUCKBERG, G.D. Depressed cardiac performance after mitral valve replacement: a problem of myocardial preservation during operation. Circulation S1: 52 Suppl. 1, 3-7 (1975).

19. HOOKER, D.R. On recovery of the heart in electric shock. American Journal of Physiology 91: 305-328 (1930).

20. Ringer's J. Physiology 4: 29-44 (1883).

21. Schaff, H.V., Dumbroff, R, Flaherty, J.T., Buckley, B., Hutchins, M. Goldman, R.A.\& Gorr, V.L. Effect of potassium cardioplegia on myocardial ischaemia and post-arrest ventricular functions. Circulation 58: 240-249(1978).

22. Ellis, R.J., Pryor, W. \& Egert, P.A. Advantages of potassium cardioplegia and perfusion hypothermia in left ventricular hypertrophy. Ann. Thoracic Surgery 24: 299-306 (1976).

23. Cunningham, J.N. Jnr., Abbas, J.S., Adams, Px., Nathan, J., Klugman, I. \& Spencer, F.C. Constant pressure aortic root perfusion versus cardioplegia and hypothermia. Comparison of methods of myocardial protection. 77; 496-503 (1979).

24. Rovetto, M.S., Whitmer, J.T. \& NeEly, J.R. Comparisons of the effects of anoxia and wholehear ischaemia on carbohydrate utilization in isolated working rat hearts. Circulation research 32: 699-771 (1973).

25. Nelson, R.L., Goldstein, S.M., McConnell, D.M. Malony, J.V. \& BUCKBERG, G.D. Improved myocardial performance after aortic cross clamping by combining pharmacological arrest with topical hypothermia. Circulation Supp. 3. Cardiovascular Surgery 54: 111, 11-16(1976).

26. Hearse, D.J., Stewart, D.A. \& Braimbridge, M.V. Cellular protection during myocardial ischaemia: the development and characterization of a procedure for the induction of reversible ischaemic arrest. Circulation 54: 193-202 (1976).

27. Kaul, T.K., Groom, M., Walker, D.R. \& Wat. SON, D.A. Myocardial protection during prolonged aortic cross clamping. VIII World Congress of International Cardiovascular Society. San Francisco. Sept. 1979.

28. Lolley, D.M., Ray, J.F., Myers, W.O. \& SAUT. TER, R.D. Myocardial protection (Letter to the Editor). J. Thoracic \& Cardiovascular Surgery 77: 631-632 (1979).

29. Bretschneider, J., Lubner, G., Knoll, D., Lohr, B., Norbeck, H. \& Aplekerman, P.G. 
Myocardial resistance and tolerance to ischaemia: phy siological and biochemical basis. J. Thoracic \& Cardiovascular Surgery 16: 241-260 (1975).

30. Kirsch, V., Rodewald, G. \& Kalmar, P. Induced ischaemic arrest. Clinical experiences with cardioplegia in open-heart surgery. J. Thoracic \& Cardiovascular Surgery 63: 121-130 (1972).

31. Hearse, D.J., Stewart, D.A. \& Braimbridge, M.V. Myocardial protection during bypass and arrest. J. Thoracic \& Cardiovascular Surgery 72: 880-884 (1976).

32. Crayer, J.M., Sams, A.B. \& Hatcher, C.R. JR. Potassium-induced cardioplegia additive protection against ischaemic myocardial injury during coronary revascularization. J. Thoracic \& Cardiovascular Surgery 76: 24-27 (1978).

33. Kirklin. J.W., Conti, V.R. \& Blackstone, E.H. Prevention of myocardial damage during cardiac operations. New England Journal of Medicine 301: 135-141 (1979).

34. Gharagozloo, F., Bulkley, B.H., Hutchins, G.M., Bixler, T.J., SchafF, H.V., Flaherty, J.T. \& Gardener, T.J. Potassium-induced cardioplegia during normothermic cardiac arrest: morphological study of the effect of varying concentrations of potassium on myocardial anoxic injury. J. Thoracic \& Cardiovascular Surgery 77 : 602-607(1979).

35. Lam, C.R., Geogme, Gnat. \& Lepore, A. Induced cardiac arrest for intracardiac surgical procedures. J. Thoracic Surgery 30: 620-625 (1965).

36. Helmsworth, J.A., Kaplan, S., Clark, L.C., Mcadams, A.J., MatThew5, S.E.C. \& EDWARDS, F.K. Myocardial injury associated with asytole induced with potassium citrate. Ann. Surgery 149: 200 (1959).

37. Effler, D.B., Knight, H.F., Groves, L.K. \& KLOFF, W.F. Elective cardiac arrest for openheart surgery. Surg. Gynae. \& Obst. 105: 407-416 (1957).

38. GAY, W.A. \& EBERT, P.A. Functional metabolic and morphological effects of potassium-induced cardioplegia. Surgery 74: 283-290 (1973).

39. Follette, D., Fey, K., Mulder, D., Maloney, J.K. JR. \& Buckbero, G.D. Prolonged safe aortic clamping by combining membrane stabilization: Multidose cardioplegia and appropriate pH perfusion. J. Thoracic \& Cardiovascular Surgery 74 : 682-689 (1977)

40. Kaul, T.K., Watson, D.A., Fortune, S.J., BlacketT, R. \& WALKER, D.R. Enhanced anaerobiosis in global and regional ischaemia. $J$, Molecular \& Cellular cardiology suppl. 2 (1979).

41. Hearse, D.J., Stewart, D.A. \& Braimbridge,
M.V. Myocardial protection during ischaemic cardiac arrest: possible deleterious effect of glucose mannital in coronary infusate. J. Thoracic \& Cardiovascular Surgery 76: 16-23 (1978).

42. RaHN, H., Reeves, R.B. \& Howel.l, B.J. Hydrogen ion regulation. Temperature and evolution. American review of respiratory diseases. 1/2: 165-172(1975).

43. Mulder, D.G. Technique for cardioplegia. J. Thoracic \& Cardiovascular Surgery 77: 325-326 (1979).

44. Jynge, P., Norway, T., Hearse, D.J., Leiris, J. de., Feuvray, D. \& Bralmbridge, M.V. Protection of the ischaemic myocardium: ultrastructive enzymatic and functional assessment of the efficacy of various cardioplegic infusates. $J$. Thoracic \& Cardiovascular Surgery 76: 2-5 (1978).

45. Braimbridge, M.V. Equipment for inducing cold cardioplegic arrest. J. Thoracic \& Cardiovascular Surgery 77: 323-324 (1979).

46. Englemen, R.M., Auvil, J., O'Donoghue, M.J. \& LEVITSKY's The signiticance of multidose cardioplegia and hypothermia in myocardial preservation during ischaemic arrest. J. Thoracic \& Cardiovascular Surgery 555-563 (1978).

47. JENNING, R.B., Early phase of myocardial ischaemia injury and infarction. American Journal of Cardiology 24: 753 (1976).

48. Danforth, W.H., NaEgle, S. \& Bing, R.J. Effect of ischaemia and re-oxygenation of glycolytic reactions and adenosine triphosphate in heart muscle. Circulation Research 8: 965-97I (1960).

49. Apstein, C.S., Decklbaum, L., Mueller, M., Hagopian, L. \& HoOd. W.B. JR. Graded global ischaemia and reperfusion: cardiac function and lactate metabolism. Circulation 55: 864-872 (1977).

50. Conn, H.L., WoOd, J.C. \& Morazes, G.S. Rate of change in myocardial glycogen and lactic acid following arrest of coronary circulation. Circula. tion research 7: 721-727 (1959).

51. Engedal, H., Skagseth, E., Saetersdal, T.S. \& MYKLeBust, R. Cardiac hypothermia evaluated by ultrastructural studies in man. J. Thoracic \& Cardiovascular Surgery 75: 548-554 (1978).

52. MCGregor, D.C., Willson, G.J, Tanaka, S, Holness, D.E., Silver, M.D., Rubis, L.J., Goldstein, W. \& Grunstenson, J. Ischaemic contracture of left ventricle. Production and prevention. J. Thoracic \& Cardiovascular Surgery 70 : 945-953 (1975)

53. RudOlPH, A.M. \& Heyman, M.A. Circulation of the fetus in uterus. Methods for studying distribution of blood flow cardiac output and organ blood flow. Circulation Research 21: 163-184 (1967).

\section{RÉSUMÉ}

Il y a plus de 20 ans que la cardioplégie (usage d'agents pharmacologiques pour induire l'arrêt électro-mécanique au çeur) a été intraduite en pratique dans le but d'obtenir des conditions idéales à la chirurgie cardiaque. Depuis, un nombre considérable de variations dans les ingrédients des solutions et leurs proportions ont été proposées et leur évaluation a fait l'objet d'études continues en laboratoire et en clinique. Toute modification à la composition d'une solution devrait faire l'objet d'une étude en laboratoire et l'on devrait porter une attention particulière dans la formulation de nouvelles solutions aux extrèmes des concentrations ioniques, du $\mathrm{pH}$ et de l'osmolarité. On n'a pas trouvé d'avantages à la cardioplégie au sang froid par comparaison aux solutions exsangues habituelles. L'emploi de solutions exsanges 
glacées associé à un refroidissement de surface du myocarde, fournit une meilleure protection que l'hypothermie de surface isolée ou l'usage d'une solution cardioplégique normothermique. La perfusion continue de la solution cardioplégique n'est pas supérieure à l'administration intermittente de solution. L'emploi combiné de cardioplégie administrée de façon intermittente, avec une hypothermie systémique modérée et une hypothermie de surfacc du myocarde, fournit une bonne protection et permet des clampages aortiques prolongés (jusqu'à deux heures). Il ne fait aucun doute que l'emploi de cardioplégie au cours des dernières années a contribué à l'amélioration du pronostic chirurgical de nombreux patients présentant des pathologies cardiaques complexes. 